\title{
PAREDES DE ESCALADA EM AMBIENTE ARTIFICIAL E NATURAL NA CIDADE $^{1}$
}

Recebido em: 06/05/2017

Aceito em: 17/01/2018

\author{
Tony Honorato ${ }^{2}$ \\ Nayara Teixeira ${ }^{3}$ \\ Ernani Xavier Filho ${ }^{4}$ \\ Universidade Estadual de Londrina (UEL) \\ Londrina - PR - Brasil
}

RESUMO: O estudo analisou as paredes de escalada disponíveis na cidade Londrina/PR. A pesquisa, de natureza qualitativa e descritiva, contou com dados coletados a partir de observações registradas por meio de caderno de campo e de imagens fotográficas. Autores como Costa (2000); Marinho (2001); Pereira (2007); Lipovetsky (2007) e Le Breton (2010) colaboram com a análise. Como resultado, foram identificados seis lugares para a pratica de escalada, sendo cinco paredes em ambientes artificiais e uma em ambiente natural.

PALAVRAS CHAVE: Atividades de Lazer. Área Urbana. Instalações Esportivas e Recreacionais.

\section{CLIMBING WALLS IN ARTIFICIAL AND NATURAL ATMOSPHERE IN THE CITY}

ABSTRACT: The study examined the climbing walls available in the city de Londrina/PR. The research, from qualitative and descriptive nature, had collected data from observations recorded through a field notebook and photographic images. Authors such as Costa (2000); Marinho (2001); Pereira (2007); Lipovetsky (2007) and Le Breton (2010) collaborate with the analysis. As a result, six places were identified for climbing, with five walls in artificial atmospheres and one wall in a natural atmosphere.

KEYWORDS: Leisure Activities. Urban Area. Sports and Recreational Facilities.

\footnotetext{
${ }^{1}$ Este artigo resulta de projetos financiados pela Fundação Araucária de Apoio ao Desenvolvimento Científico e Tecnológico do Paraná e pelo FAEP/UEL.

${ }^{2}$ Pós-doutor, Doutor e Mestre em Educação. Licenciado em Educação Física. Professor do Departamento de Educação Física e do Programa de Pós-Graduação em Educação da Universidade Estadual de Londrina. Membro do Grupo de Escalada do CEFE/UEL.

${ }^{3}$ Bacharel em Educação Física e Especialista em Treinamento Esportivo pela Universidade Estadual de Londrina - UEL. Grupo de Escalada do CEFE/UEL

${ }^{4}$ Doutor e Mestre em Educação Física pela Universidade de São Paulo - USP. Professor do Departamento de Educação Física da Universidade Estadual de Londrina - UEL. Membro do Grupo de Estudos em Desenvolvimento e Aprendizagem Motora de Crianças com Desenvolvimento Atípico. Grupo de Escalada do CEFE/UEL.
} 


\section{Introdução}

A escalada, bem como o montanhismo e o alpinismo, é praticada desde que o homem começou a explorar a natureza e vem sendo cada vez mais desenvolvida na sociedade moderna. Ao longo do tempo, ela ganhou novas formas de prática e de tecnologia permitindo, por meio de equipamentos, uma vivência com mais recurso de segurança. Com a disseminação da escalada pelo mundo, muitas pessoas foram aderindo a essa prática esportiva e de lazer de aventura. Sendo que independentemente da localidade, o indivíduo pode vivenciar situações de emoção e risco calculado (HONORATO; XAVIER FILHO, 2013).

Embora a escalada tenha surgido em ambiente natural, pela necessidade do homem de explorar o desconhecido, os rigorosos invernos limitavam a atividade do escalador. Para suprir essa necessidade, na Ucrânia na década de 1970, foram criadas as paredes artificiais em ginásios, a chamada escalada indoor. (PEREIRA, 2007)

Em cidades que não possuíam grandes paredes rochosas ou montanhosas, os aficionados da modalidade criaram ambientes artificiais de escalada. Entende-se por ambiente artificial de escalada um local, indoor ou não, constituído por paredes formadas por agarras e caminhos artificiais montados por uma pessoa ou uma equipe. Tal ambiente possibilita a escalada em diversos horários, logo atendendo os praticantes em termos de tempo, finalidades e estilo de vida.

Não se nega que o modo de vida urbano está cada vez mais dinâmico e o homem luta contra o tempo do relógio. Por sua vez, a sensação de violência também tem aumentado. Esses são alguns dos motivos que levaram o homem a buscar por alternativas de atividades como a escalada no meio urbano minimizando os riscos e maximizando o aproveitamento do tempo que pouco sobra no modo de vida na modernidade capitalista. 
Para Marinho (2001), há uma forte tendência de trazer o "natural" para os padrões urbanos. O homem busca trazer os desafios da natureza para a cidade da forma mais parecida possível com o natural. Na escalada destaca-se, por exemplo, que as agarras artificiais (saliência ou fenda na qual se coloca as mãos ou pés na escalada) têm texturas feitas de areia e resina sendo parecidas com rochas naturais.

Considerando que cada cidade tem sua cultura local, que contribui de certa maneira com a disseminação da escalada, optamos por pesquisar a escalada na cidade de Londrina, localizada no norte do Estado do Paraná, onde tal atividade incorpora adeptos crescentemente.

Em Londrina, podem-se encontrar locais para se escalar, porém alguns já desativados por falta de manutenção, cuidados e recursos financeiros. Na localidade, também temos observado falhas na divulgação de informações e orientações sobre tal prática, objetivadas em perguntas do tipo: "Existem lugares para escalar em Londrina?”; “Onde?”; “Com quem devo falar?”; “Quem pode me levar?”; “O que preciso para escalar?”. Por vezes, as repostas são emitidas pelos esforços dos escaladores via organização de eventos ${ }^{5}$, palestras, fanpages no Facebook, círculos de convivência.

Assim, desejando potencializar informações e reflexões sobre a realidade, a nossa pesquisa teve como questão central identificar os lugares onde os escaladores e demais interessados suprem a necessidade de escalar em Londrina. O objetivo geral consistiu em realizar um mapeamento e descrever as paredes de escaladas (indoor ou não) em ambientes artificiais e naturais situados na cidade de Londrina/PR.

\footnotetext{
${ }^{5}$ Em Londrina e região, anualmente, é realizado o "Encontro de Escalada", promovido pelo Clube de Montanha Norte Paranaense.
} 


\section{Métodos}

Realizamos uma pesquisa de natureza qualitativa do tipo descritiva. Esta não é apenas uma dimensão não quantitativa, mais busca detalhar como as pessoas constroem o mundo à sua volta, o que estão fazendo e como os acontecimentos fazem sentidos. O valor da pesquisa descritiva baseia-se na premissa que os problemas podem ser discutidos e até solucionados por meio da observação objetiva e minuciosa, da descrição e análise (MOREIRA; CALEFFE, 2008). Desse modo, consideramos as características situacionais apresentadas pelos indivíduos e o uso social dos lugares de se escalar, isso por meio da observação como técnica de constatar a realidade.

Alguns cuidados foram tomados ao realizarmos a observação da realidade. Seguindo as orientações de Triviños (1995), primeiramente balizamos qual era a nossa função na pesquisa. Na condição de pesquisadores temos os nossos valores, os quais puderam diferir da realidade, logo buscamos interferir o mínimo possível na ordem social observada. Em segundo momento, nos atentamos aos detalhes, como as principais características e formatos do que foi observado e registrado.

A nossa observação contou com uma amostragem de tempo e anotações de campo. A amostragem de tempo foi o período definido para os pesquisadores visitarem os locais, cada visitação teve duração de aproximadamente duas horas e cada local recebeu-nos por duas vezes, definição aleatória. Já os dados de campo foram os registros durante as observações. Não foi um processo simples, pois exigiu dos pesquisadores atenção à realidade e à dimensão explicativa requerida pelos dados produzidos.

Como instrumento de coleta de dados, utilizamos para as anotações um caderno de campo, no qual foram registradas as observações e reflexões sobre as expressões dos frequentadores das paredes de escalada. E os elementos estruturais dos 
locais observados foram também capturados por meio de uma câmera fotográfica, gerando uma série de imagens.

Ainda, conforme Triviños (1995), as anotações de campo se dividem em descritivas e reflexivas. Para as anotações do tipo descritivo, assumimos as seguintes orientações: a) descrever os comportamentos, ações e atitudes, tal como eles se oferecem à observação; b) descrever os sujeitos não em forma abstrata, senão por seus traços concretos; c) descrever um meio físico; d) descrever atividades específicas.

Desse modo, para a produção dos dados trilhamos os caminhos:

$1^{\circ}$.) Identificação da localização de parede de escalada: foram visitadas as paredes em ambientes naturais e artificiais de Londrina/PR. Para chegar às informações, contou-se com os conhecimentos prévios dos investigadores e escaladores locais foram consultados. A partir de então, em cada local, buscamos identificar informações sobre outras possíveis paredes existentes.

$2^{\circ}$.) Registro das observações: para registrar e organizar os dados tomamos os seguintes indicadores na produção do caderno de campo:

a) Localização da parede: Nome do local; Endereço completo;

b) Caracterização econômico-social da parede: Administração da parede (pública/ privada); Taxa de uso; Como se dá o acesso; Meios de divulgação; Público alvo.

c) Caracterização geral da parede: Tipo de parede; Modalidade(s) ofertada(s); Dimensões físicas; Existência de cobertura e iluminação no local; Tipos de agarras; Material de segurança disponível; Tipo de ancoragem; Vias existentes; Graus de dificuldade.

d) Caracterização do público frequentador: Existência de instrutor; Formação do instrutor; Faixa etária dos praticantes; Existência de grupos de 
escaladores; Níveis de experiência/vias; Proprietários dos equipamentos; Vestuário dos frequentadores.

\section{Resultados}

Os resultados são advindos das observações em três academias de ginástica, uma escola de circo, um clube social-recreativo e uma "pedreira" natural. Todos ambientes localizados na cidade de Londrina/PR. Os resultados foram organizados em dois grupos: paredes de escalada em ambientes artificiais e parede de escalada em ambiente natural.

\section{Paredes de escalada em ambientes artificiais}

\section{Academia Energy Gym}

A Academia Energy Gym está localizada em frente ao lago Igapó II, uma região privilegiada para praticar atividade física na cidade de Londrina. O bairro é conhecido por ser de classe econômica média alta. A Academia situa-se na Rua Bento Munhoz da Rocha Neto, n. 527, Jardim Gleba Palhano.

Além da escalada, há várias outras atividades ofertadas, tais como: musculação, pilates, jump, ginástica aeróbica, step, runner team, alongamento, aula de abdominal, exercícios para a postura, aula para glúteo, legup, power move, entre outras, contanto também com os serviços de uma nutricionista. 
Figura 1 - Parede de Escalada (Top Rope e Boulder)

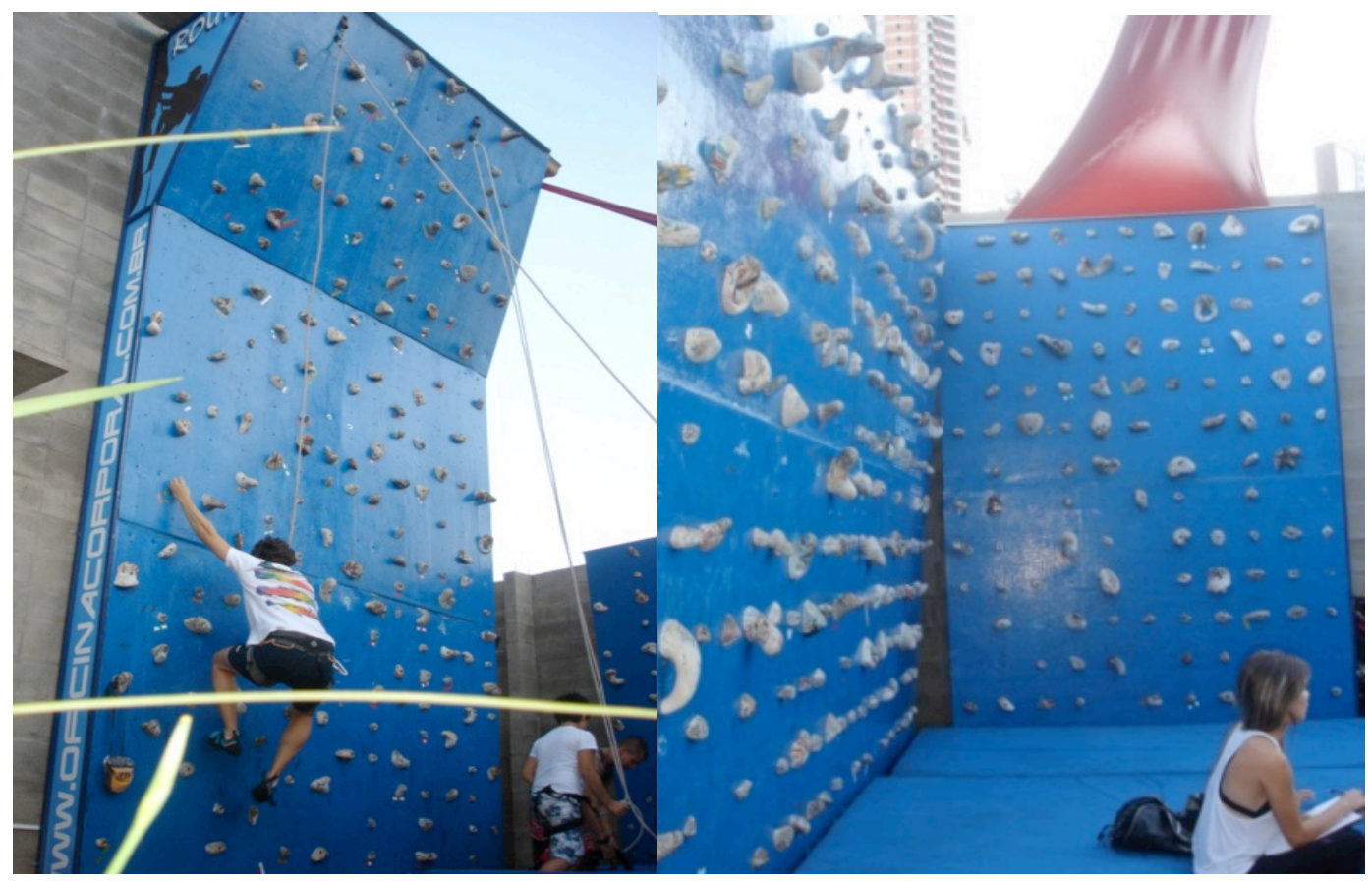

Fonte: Arquivo pessoal.

A parede é uma iniciativa privada e terceirizada que não pertence à Academia, são três sócios proponentes e administradores da atividade. Para uso, o valor mensal é de $\mathrm{R} \$ 80,00$ e o diário é de $\mathrm{R} \$ 15,00$.

A chegada até o local se dá por vias públicas na área urbana, já o acesso à parede corre por dentro da Academia. No final da tarde, é aberto um portão que dá acesso direto à parede, pelo corredor lateral do estabelecimento. O público é configurado por-indivíduos interessados em escalar, não há restrições de idade, experiência ou nível elevado de condicionamento físico. Para atingir esse público, a divulgação é feita através das redes sociais, "boca-boca" e distribuição de folders.

A parede é construída em compensado naval $18 \mathrm{~mm}$, pintado de azul. São ofertadas duas modalidades: Top Rope $e^{6}$ medindo 3,4m de largura x 6,6m de altura;

\footnotetext{
${ }^{6}$ Corda vinda do alto. Trata-se de um tipo de escalada praticada com a corda previamente fixada no topo da via.
} 
Boulder $^{7}$ reto medindo 2,5m largura x 3,2m altura; e um Boulder negativo com 5,0m largura x 3,2 altura; compondo uma área total para a prática de $50 \mathrm{~m}^{2}$ a qual não possui cobertura, o que dificulta a prática em dias de chuva, mas conta com iluminação própria. A ancoragem de cordas é feita por meio de correntes fixadas no topo da parede. Na modalidade Top Rope há 10 vias $^{8}$ marcadas e no Boulder são 10 vias com um grau de dificuldade que varia de um $4^{\circ}$ até um $7^{\circ}$ grau 9 .

As agarras são artificiais, com diversos tipos de pegadas (reglet, bidedo, mão aberta, mão fechada) ${ }^{10}$. Possui materiais próprios de segurança como colchões de proteção no chão, ao redor há piso emborrachado, cadeirinhas de diversos tamanhos, mosquetão rosca, corda estática, magnésio, saco de magnésio, sapatilhas de diferentes tamanhos, freio " 8 " e freio grigri.

Para atender os interessados, conta com 2 instrutores, sendo 1 formado em Educação Física e o outro estagiário graduando em curso de Educação Física. No momento da pesquisa, eles estavam responsáveis por 17 alunos de faixa etária entre 12 e 30 anos, em sua maioria iniciantes na escalada, pois nota-se que eles mantêm o corpo afastado da parede e pegam nas agarras sem técnica de escalador.

Os frequentadores costumam escalar em grupo de 5 a 6 pessoas e, por não terem equipamentos próprios, utilizam-se dos materiais disponibilizados pelos administradores da parede. As vestimentas utilizadas eram bermudas, camisetas, tênis e roupas de fitness.

\footnotetext{
${ }^{7}$ Escalada praticada em blocos de rocha ou em paredes artificiais de dois a cinco metros de altura, o que pode ser escalado sem uso de equipamentos de segurança característicos da escalada. Segundo Pereira (2007), o maior desafio no Boulder é escalar situação problema.

${ }^{8}$ Caminho que se escala, planejado com grau de dificuldade.

${ }^{9}$ Para uma classificação de graus de dificuldades em escaladas, conferir Pereira (2007).

${ }^{10}$ Alguns tipos de pegadas exigidas pelos modelos de agarras: estendida - não fecha a mão, apenas apoia; fechada - todos os dedos seguram uma agarra; pinça - o polegar faz oposição aos outros dedos; bidedo - orifícios que cabem apenas 2 dedos; reglets - são agarras pequenas que cabem apenas as pontas dos dedos.
} 


\section{Academia Body \& Soul Club}

A Academia Body \& Soul Club é um espaço amplo, com infraestrutura de excelência para trabalhos de exercícios individualizados. Está instalada em uma região nobre da cidade de Londrina na Rua Rubens Carlos de Jesus, n. 420, Bairro Terra de Santana II, onde estão localizados condomínios residenciais de alto padrão.

Além da escalada, a Academia oferece diversos serviços: fisioterapia, massoterapia, nutricionista. Na parte de exercícios, as modalidades são: estúdio personal, pilates, treinamento funcional, musculação e atividade infantil.

Figura 2 - Parede de escalada da Academia Body \& Soul Club

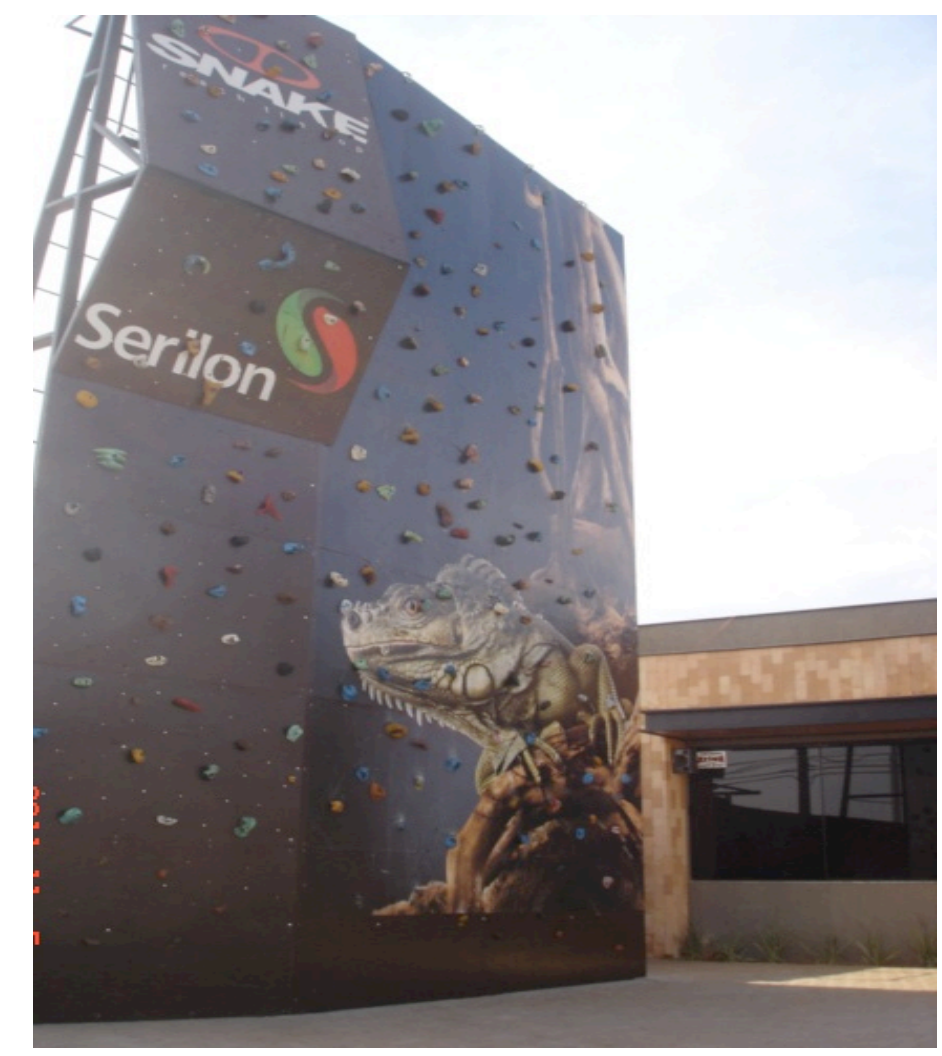

Fonte: Arquivo pessoal.

A administração da parede é de natureza privada e sob a responsabilidade do proprietário da Academia. Para a sua utilização é cobrada uma taxa que vai depender da frequência semanal eleita pelo aluno, sendo: 1 vez por semana $\mathrm{R} \$ 50,00 ; 2$ vezes 
R \$ 70,00; 3 ou mais vezes R\$ 100,00. Já o horário para treinar deve ser agendado com antecedência para se ter um responsável capacitado para atender o aluno.

O acesso até a parede se dá por vias públicas urbana. A divulgação da parede conta com a parceria da Snake (marca fabricante de sapatos específicos de atividades de aventura) - acontece nos condomínios residenciais que estão no entorno, na organização de colônias de férias para escolares, na festas e festivais. Destaca-se que o estabelecimento tem parceria com uma escola particular, uma das mais custosas da cidade, que leva alunos da educação básica para vivenciar escalada como atividade física extraclasse.

O público alvo da academia é diversificado abrangendo pessoas com diferentes idades e residentes na região próxima ao local do estabelecimento.

A parede é artificial feita em compensado naval, medindo 8 metros de altura por 6 metros de largura, conta com fundo escuro contrastando com a imagem de um lagarto. A modalidade ofertada é a Top Rope, possui iluminação, a qual se observou ser insuficiente para clarear as vias e agarras que, de certa forma, se misturam entre o fundo escuro e o desenho.

As agarras que compõem a parede são bem variadas o que pode proporcionar ao escalador o uso de diferentes técnicas de pegada, a saber: mão fechada, reglet, bidedo, tridedo, pegada com a mão aberta. Para desenvolver a ascensão, a Academia possui seus materiais próprios, como: cadeirinhas, mosquetão rosca, corda, freio ATC. A ancoragem é fixa por meio de um mosquetão de construção civil.

A arte do desenho contou com patrocínio de uma empresa de plotagem e a distribuição das agarras na parede foi realizada por meio da colaboração de um escalador (Adilson Koizume). Apenas uma via foi marcada (amarela), pois geralmente as vias são estabelecidas pelas cores das agarras ou por fitas adesivas de 
diferentes cores, fazendo com que o grau de dificuldade geral da parede seja bem variado, podendo o praticante eleger o caminho da subida de acordo com o seu nível técnico e de desejo.

Sobre os frequentadores observamos que eles estavam no nível inicial de escalada. Os instrutores indicados para atender alunos eram estagiários, graduandos em curso de Educação Física. Segundo o proprietário, eles recebem uma capacitação para orientar os interessados na modalidade.

\section{Academia Pura Vida}

A Academia Pura Vida está localizada no centro da cidade de Londrina, na Rua Senador Souza Naves, n. 873. Um espaço amplo, oferta atividades como: musculação, jump, ginástica localizada, yoga, pilates, jiu-jitsu, kickboxing, muaythai, taekwondo, cursos de defesa pessoal, personal training, escalada.

Figura 3 - Parede de Escalada da Academia Pura Vida

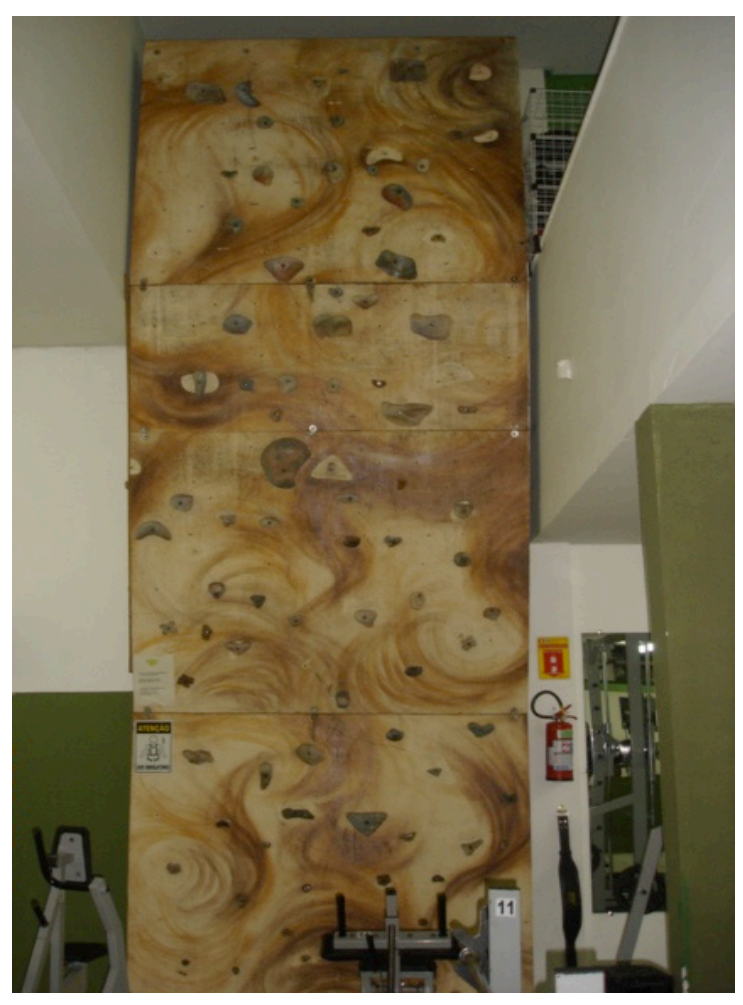

Fonte: Arquivo pessoal. 
A administração da parede é de iniciativa privada e assim como os demais serviços ofertados na Academia, a sua gestão fica a encargo do proprietário. Não é cobrada taxa extra de uso da parede para os alunos matriculados na Academia, sendo de livre acesso para utilizar quando quiserem. A chegada à Academia se dá pelas vias públicas. E o acesso a parede de escalada é feito pelo interior do estabelecimento, atravessando a área dos aparelhos de musculação.

A divulgação da parede é realizada simultaneamente com a da Academia por meio de folder, site, e-mail comercial. O público alvo é constituído por adultos entre 20 a 30 anos de idade.

A parede é indoor, o material utilizado na sua construção é compensado naval. A modalidade ofertada é a Top Rope e tem dimensões de 6 metros de altura por 2,2 metros de largura, instalada em um local bem iluminado. A parte inicial (saída) de escalada na parede, até a metade, é reta $\left(90^{\circ}\right)$, já na parte final há uma leve inclinação que aumenta o grau de dificuldade da ascensão.

As agarras são artificiais variando o tipo de pegada: reglet, bidedo, tridedo, mão aberta, pegada de "bote". Não há muita variedade e quantidade de materiais de segurança, mas entre eles estão: cadeirinhas, mosquetão rosca, corda, freio. Pois neste estabelecimento, quem mais utiliza a parede são escaladores detentores de equipamentos próprios. A ancoragem é do tipo "P" (gancho de aço). As vias foram marcadas por um escalador (Urias Ferreira), os graus de dificuldade atendem o nível de experiência de iniciante, intermediário e avançado.

A frequência de alunos e escaladores na parede é muito baixa. Assim, não é economicamente viável para a Academia manter um instrutor. Evidência disso são os aparelhos de musculação que dividem área com a escalada (Figura 3). Contudo, 
segundo o proprietário, a parede foi instalada com o intuito de buscar um diferencial em relação à outras academias.

\section{Clube Poliesportivo Grêmio Londrinense}

O Clube Poliesportivo Grêmio Londrinense, situado na Rua Grafitta, n. 332, no Jardim Ideal, Londrina. O Clube desfruta de infraestrutura com piscinas, churrasqueiras, quadras, academia e oferta modalidades esportivas e recreativas, entre elas: futsal, futebol, voleibol, tênis, arvorismo, paintbal, hidroginástica, natação, musculação. Muitas dessas atividades são pagas a parte e os sócios do Clube têm desconto.

Figura 4 - Parede de Escalada do Grêmio Londrinense

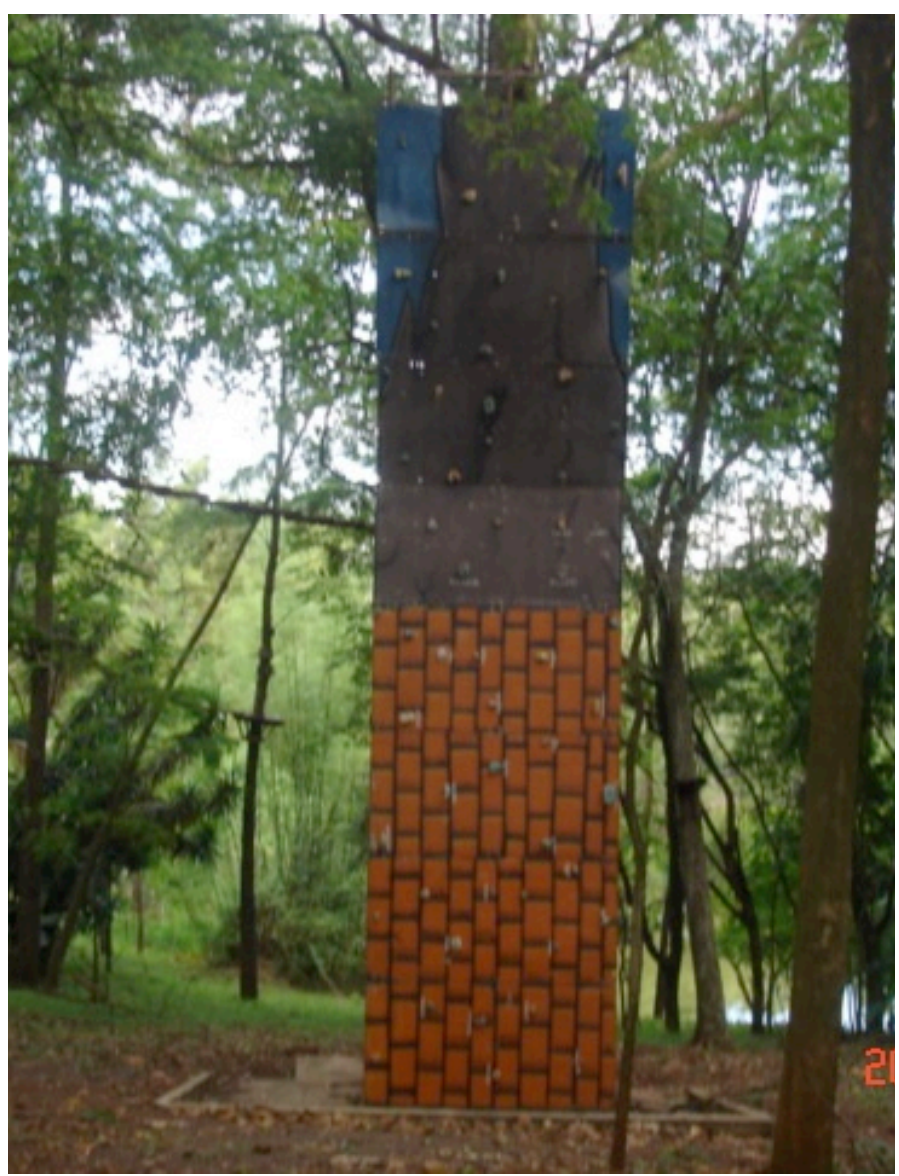

Fonte: Arquivo pessoal. 
A parede é de iniciativa privada e não é administrada pelo Clube. O lugar é alugado por uma equipe de atividade de aventura, coordenada pelo Armando (popularmente conhecido como "Armandão") que também administra o paintbal e o arvorismo. A taxa de uso da parede é cobrada juntamente com os pacotes fechados envolvendo as outras duas atividades, variando os preços de acordo com a quantidade de pessoas e atividades a serem realizadas. Para acessar a parede, é necessário passar pelas instalações do Clube. A parede é divulgada entre os frequentadores do Clube e a para as pessoas da região do entorno, atendendo os sócios, funcionários de empresas e escolares.

A parede é artificial, feita de compensado nas dimensões 2,20 metros de largura por 9,0 metros de altura, sem cobertura e o local é pouco iluminado a noite. São ofertadas apenas a modalidade Top Rope. Destaca-se a ausência de chapeletas ${ }^{11}$ até o ponto de ancoragem. Quanto às agarras, são todas artificiais de fácil manejo e pegada com grande superfície de contato para os pés e as mãos. Assim, há vias com graus de dificuldade mais fácil e apenas uma via foi marcada. O material de segurança utilizado é o mesmo do arvorismo: cadeirinhas, mosquetões, freios e cordas.

Para instruir a escalada, a equipe conta com estagiários que desenvolvem atividades também no arvorismo. Eles atendem um público, geralmente organizado em grupos, com faixa etária de 12 a 40 anos, e que teve pouco ou nenhum contato com a escalada. Os participantes comumente usam uniformes escolares ou roupas esportivas.

A parede encontra-se aparentemente subutilizada, episodicamente também é alugada para eventos. Escaladores, conhecidos do coordenador, utilizam a parede eventualmente. A quantidade de folhas, a falta de manutenção das agarras e a

\footnotetext{
${ }^{11}$ Chapeleta: feita por um mosquetão de aço, por meio dela a corda é levada até o topo, formando uma espécie de "escada" que garante maior segurança para quem irá montar o Top Rope.
} 
ausência de pessoas na área onde se encontra a parede e a falta de resquícios de magnésio nas agarras (Figura 5), indica que a parede está subutilizada.

Figura 5 - Condições da parede do Grêmio.

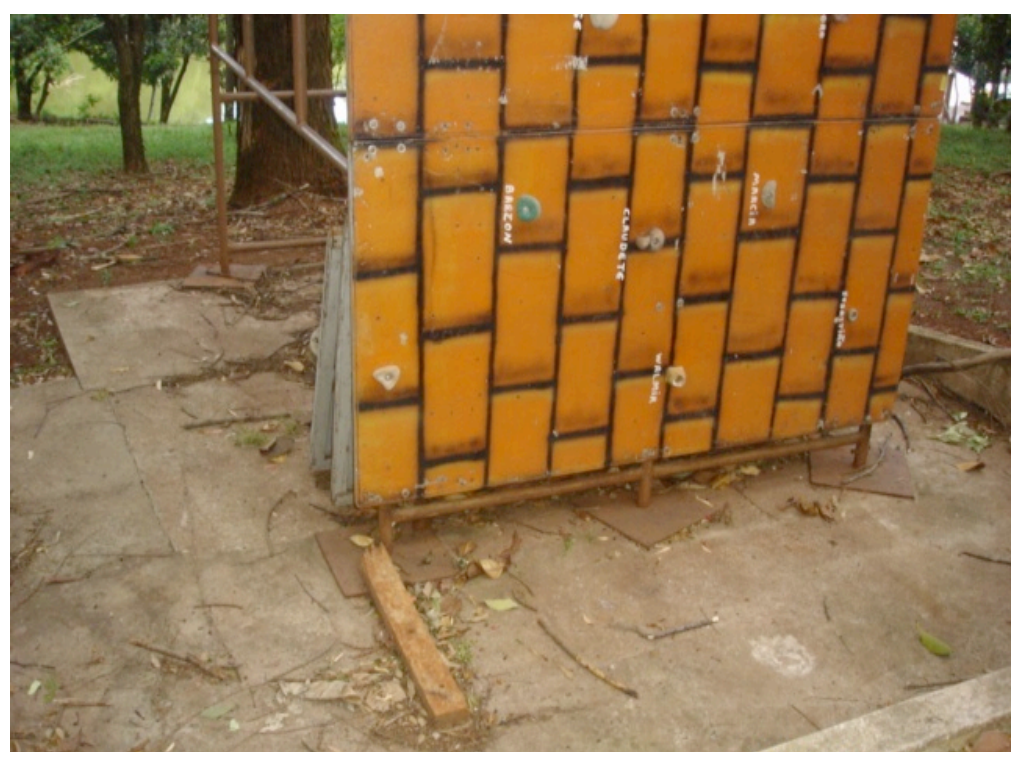

Fonte: Arquivo pessoal.

\section{Escola de Circo "Clac"}

A Escola de Circo "Clac" está situada na Rua Professor Samuel Moura, n. 451, no Jardim dos Bancários. A “Clac” é um espaço criado e adaptado para aprender e aperfeiçoar as técnicas circenses, por esse motivo são ofertadas as modalidades: cama elástica, tecido (marino), mini-trampolim, acrobacia de solo, malabarismo, arame, equilíbrio, monociclo, trapézio fixo e lira (argola). 
Figura 6 - Parede de Escalada do "Clac"

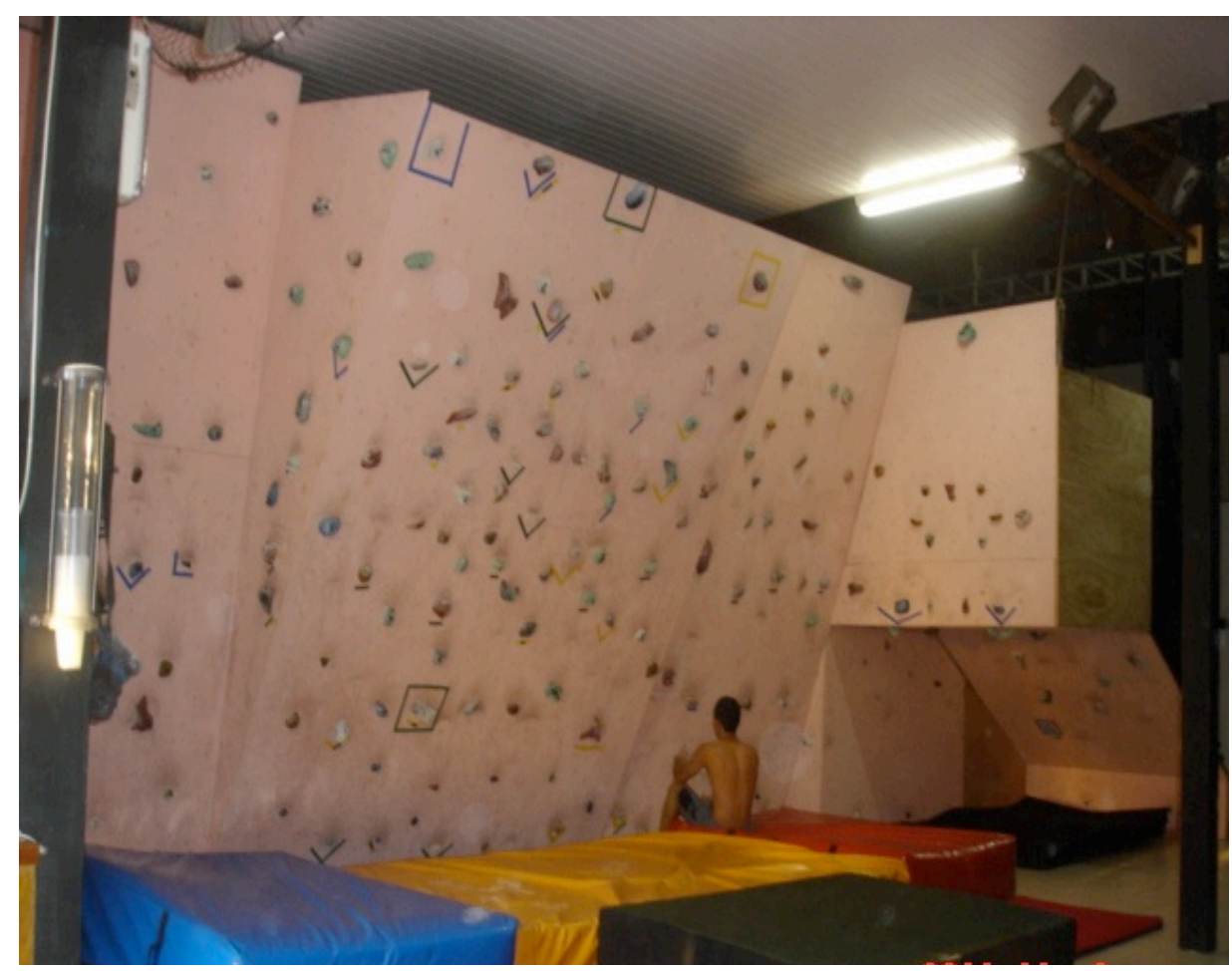

Fonte: Arquivo pessoal.

A iniciativa de construir a parede do tipo Boulder na "Clac" é privada, idealizada por um escalador (Luiz Eduardo) que já atuava na área circense e também é o administrador de toda a Escola. $\mathrm{O}$ acesso à parede é fácil, primeiro por estar no centro da cidade e ser um lugar conhecido pela população. Para manter o local, há taxa de uso de $\mathrm{R} \$ 50,00$ mensais, o atendimento é de terça a quinta-feira, das $18 \mathrm{~h} 00$ às 23 h00. Para atingir o público - escaladores ou não; crianças, jovens e adultos de ambos os sexos - o pessoal administrativo utiliza-se de redes sociais, jornal, rádio e folder.

A parede de escalada da "Clac" é artificial, feita de compensado medindo 4 metros de altura com vários graus de inclinação. As inclinações são distribuídas assim: 2 retas $\left(90^{\circ}\right) ; 1$ negativa $\left(-80^{\circ}\right) ; 1$ negativa $\left(-70^{\circ}\right) ; 1$ negativa $\left(-60^{\circ}\right)$; teto $\left(0^{\circ}\right)$ e a subida para o teto negativa $\left(-35^{\circ}\right)$. 
Como as paredes não passam de 4 metros de altura e a característica da modalidade ofertada é Boulder, não é necessário o uso de equipamentos individuais para escalar. As paredes contam com 400 agarras artificiais de diferentes formatos e tipos de pegadas: reglets, bidedo, mão aberta, abaulado.

Os principais equipamentos de segurança necessários para o Boulder são os colchões de espuma espessa, mas no estabelecimento há também sapatilhas e magnésio para quem ainda não adquiriu seus próprios acessórios. As agarras formam diversas vias, entre elas 12 foram marcadas e, no geral, vão do grau de dificuldade de um $4^{\circ}$ até um $12^{\circ}$ grau, ficando a critério do escalador escolher o grau que se sente apto em praticar.

Para acompanhar os alunos, o administrador do local, que trabalha com atividades circenses e é especializado em segurança aérea, fica à disposição para orientação ou dúvidas. Luiz Eduardo atende um público bem diversificado, desde crianças de 8 anos atingindo jovens e até adultos de 50 anos, de ambos os sexos. Todavia, não há profissionais formados em Educação Física para o acompanhamento das atividades vivenciadas no estabelecimento.

O espaço é adequado para receber o público, com banheiros (feminino e masculino), água, iluminação suficiente e boa ventilação.

O público frequentador se apresenta em grupos, mas a escalada é individual ou em dupla. Quando encontramos alguém sozinho, tratava-se de um escalador mais experiente, que nos disse treinar os movimentos para ir à rocha nos finais de semana. Os grupos maiores eram de iniciantes, pessoas que disseram gostar de escalar por lazer e para escapar da rotina estressante da vida cotidiana no meio urbano.

A parede também cumpre o papel de preparação física dos praticantes de arte circense. As roupas utilizadas pelo grupo dos alunos são bermudas, chinelos, tênis, 
roupas esportivas e leves de modo geral. Em uma visita e observação anterior, na "Pedreira do Cafezal", nos deparamos com alguns escaladores frequentadores da "Clac".

\section{Parede de escalada em ambiente natural: "Pedreira do Cafezal"}

A "Pedreira do Cafezal" está localizada em pleno perímetro urbano de Londrina, no Bairro Gleba Cafezal, na Rua Alvizio Jarreta. É um espaço de grande porte, comporta muitos escaladores ao mesmo tempo e sem a necessidade de ocuparem a mesma via de escalada. O espaço da "Pedreira" também é muito utilizado por empresas de que exploram atividades de aventura, principalmente para vivenciar o Rapel (técnica de descida utilizando corda).

Figura 7 - Pedreira do "Cafezal"

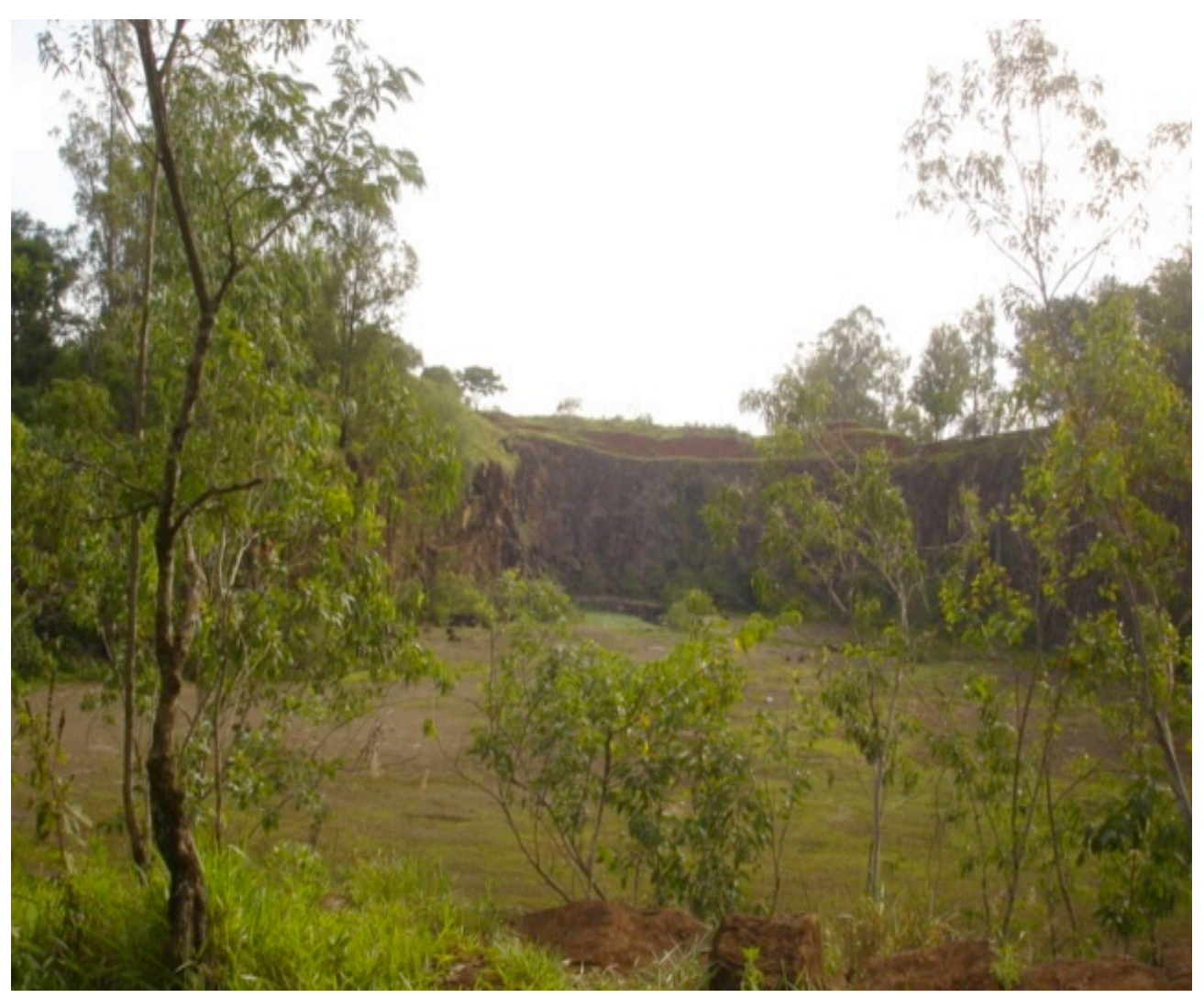

Fonte: Arquivo pessoal. 
A "Pedreira" se encontra em propriedade privada, todavia a administração da escalada está por conta dos escaladores locais e também do proprietário da terra que autoriza a entrada dos praticantes. Para utilizar o paredão formado por rochas não há taxa de uso, o que ao longo do tempo pode ser alterado de acordo com os interesses do proprietário. Para chegar à localidade, é necessário estacionar o carro em via pública e fazer uma breve caminhada de aproximadamente 300 metros em terreno irregular, por dentro da propriedade. Porém, não há um local adequado para estacionar automóveis em segurança enquanto se escala.

Não há divulgação por meio de ação de marketing, a "Pedreira" é conhecida entre os escaladores mais experientes que levam seus pares para lá e comentam entre eles. Os frequentadores, majoritariamente, homens com idade média de 20 a 40 anos, mulheres também frequentam, como é o caso de um dos membros desta pesquisa.

A atividade é praticada de forma outdoor em rocha natural basáltica. As modalidades mais comuns são: Top Rope, Escalada guiada e Escalada esportiva. A altura das vias é variada, e estas não possuem cobertura e a iluminação é natural (luz do sol); o que não falta em dias de calor é a iluminação, já a sombra é feita pelas poucas árvores e arbustos que rodeiam as rochas. As agarras são formações naturais ou antropogênicas formadas na época de exploração da "Pedreira".

Há agarras no formato de reglets, mão aberta, mão fechada, bidedo, tridedo, fendas, blocos de rocha, entre outras. Para segurança da escalada, há chapeletas e ancoragens do tipo "P". Os materiais de uso individual ficam por conta de cada escalador. Pela dimensão do espaço, não é de se assustar que haja um número significativo de vias, entre um $4^{\circ}$ e um $9^{\circ}$ grau de dificuldade. 
Figura 8 - Ancoragem e costuras/ agarras da "Pedreira"

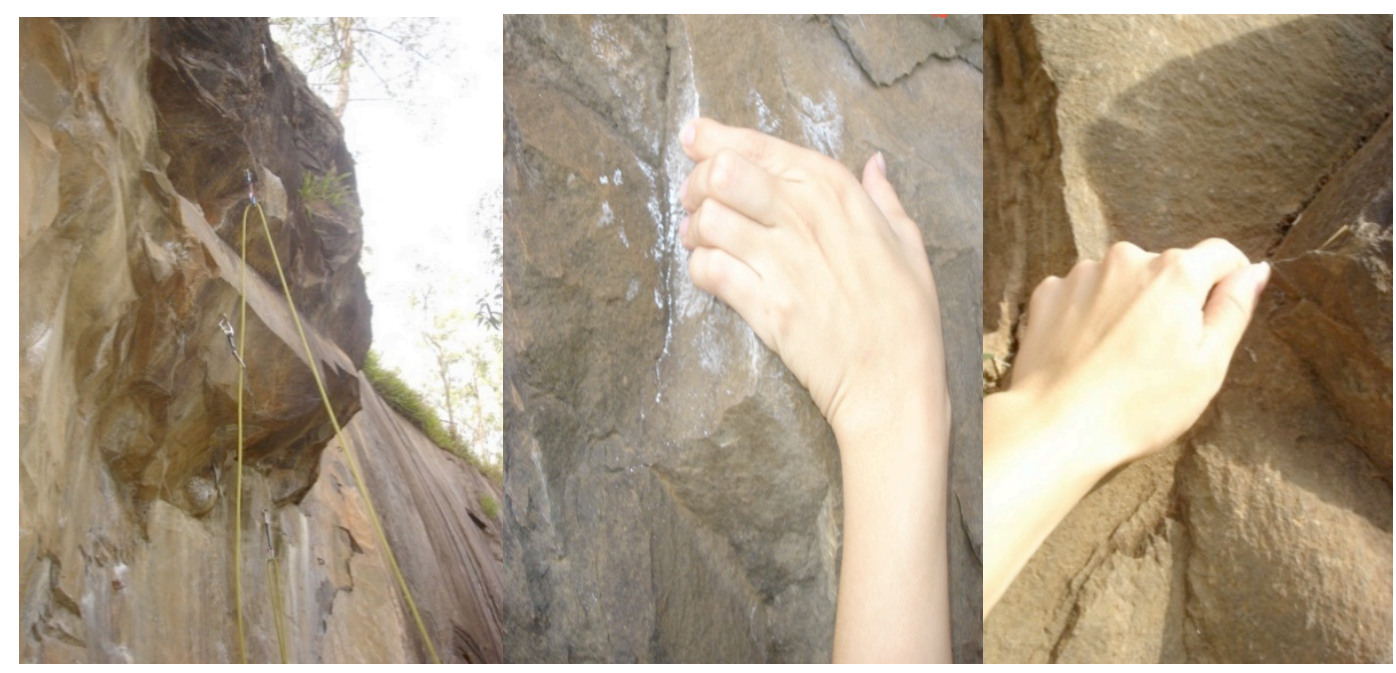

Fonte: Arquivo pessoal.

Durante a observação e nos diálogos com os escaladores, registramos a inexistência de instrutor disponível para quem quiser escalar pela primeira vez. Iniciantes geralmente vão acompanhados com os escaladores mais experientes. Os escaladores chegam em duplas ou trios, e levam os equipamentos necessários e água potável. Notamos também ser fundamental para quem faz em solo a segurança do escalador em ascensão, o uso de capacete, pois pedras podem desprender causando acidentes.

Não identificamos horário pré-definido, a "Pedreira" está aberta 24 horas e os escaladores vão chegando a todo o momento, comumente aproveitam a luz do sol e a maioria deles se conhece. Cada grupo de escaladores ocupa uma via de escalada da "Pedreira", sendo ela mais frequentada aos finais de semana. 
Figura 9 - Escaladores na "Pedreira do Cafezal"

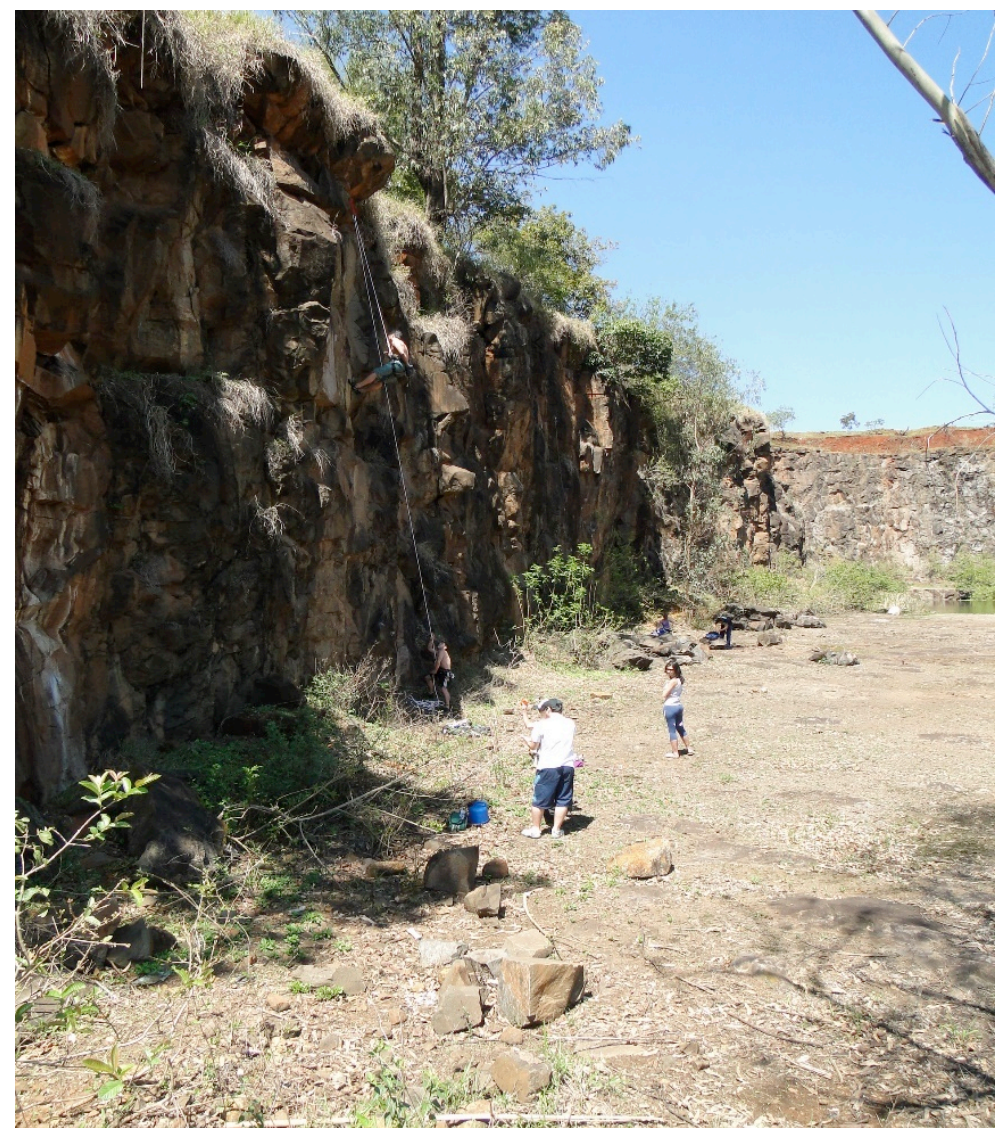

Fonte: Arquivo pessoal.

\section{Discussão}

As paredes de escalada indoor (ou não) em academias de fitness, clubes socialrecreativos e escola de circo, foram construídas com materiais artificiais (estruturas e agarras) e estão direcionadas a um público de bom poder aquisitivo. A pesquisa em Londrina revelou que as paredes estão na região central e em bairros de classe média alta, e foram pensadas e divulgadas principalmente como meio de negócio.

Constatamos que a montagem das paredes contou com a consultoria e o apoio de parceiros escaladores, e até onde identificamos, não há em Londrina equipe ou empresa especializada em montagem de paredes de escalada. Todavia, é a partir de ações isoladas que algumas atividades de aventura, segundo Bernardes (2011), começam a se difundir 
no meio urbano, bem como pela possibilidade de sua replicação com determinados materiais e equipamentos.

O público frequentador das paredes em ambientes artificiais, em sua maioria, é composto por pessoas que buscam a escalada como atividade física e/ou de lazer, e não necessariamente como prática esportiva regrada e institucionalizada. Analisando com Lipovetski (2007), tal realidade se desenvolve porque as pessoas estão socialmente mergulhadas nas possibilidades de vivência de sentimentos prazerosos e fascinadas pelos desafios, pela otimização das capacidades do corpo em consonância com a sociedade do hiperconsumo.

A escalada em ambientes artificiais urbanos revela-se como alternativa de busca por novas sensações emocionais apurando o sentido de bem-estar diretamente vinculado ao qualitativo, centrado no corpo vivido e como atividade física e de lazer a ser consumida comercialmente promovendo estilo de vida típico dos tempos atuais.

Conforme Uvinha (2010), as atividades de aventura estão cada vez mais acessíveis, cômodas e apresentam-se para a sociedade como uma manifestação de lazer. Para Marinho (2001), nos centros urbanos os ambientes artificializados destinam-se à clientela selecionada proliferam-se quantitativamente diversificando modalidades, adaptando-se as novas exigências socioculturais e estabelecendo diálogos interpessoais, pois, em especial nas paredes de escalada, as experiências cotidianas das pessoas impregnam os lugares apresentando novas formas de experimentação que levam os sujeitos ao estado de "homo ludens" e à constituição de identidades.

A experiência da prática da escalada em si, a reunião de pessoas entorno da atividade, logo os valores e linguagens praticados no seu interior, conferem aos praticantes um pertencimento social. Segundo Vargas; Silva e Amaral (2015), a prática da escalada, como experiência de lazer e de lazer significativo, representa uma 
manifestação que assumi um papel relevante no curso da vida do sujeito praticante da modalidade.

Bernardes (2011) ressalta ainda que nos ambientes artificiais as formas de controle extrapolam os códigos dos próprios frequentadores, pois fazem haver, por exemplo, um maior controle e segurança por parte dos pais. Por conseguinte, há o estímulo para que crianças e jovens vivenciem as atividades de aventura sem colocar em risco a relativa ordem social e corpórea física. Tais ambientes também colaboram com o processo de desmarginalização de algumas atividades de aventura que são consideradas perigosas e praticadas por "malucos".

No caso do Boulder identificado na Escola de Circo "Clac", a escalada, para além da esfera do lazer, tem também o intuito treinar escaladores que desejam ir ao ambiente natural nos finais de semana, bem como preparar fisicamente aqueles envolvidos com a arte circense. De acordo com Pereira (2007), a pratica de Boulder é desafiadora e difícil por exigir a formulação de linhas imaginárias geradoras de problemas a serem superados ao se utilizar de movimentos dinâmicos, intensos, curtos, longos que normalmente não permitem o ato de descansar na parede. Logo, nesta modalidade, o treino é uma alternativa para maximizar o tempo e melhorar as condições do escalar a ser empreendida em ambientes naturais.

Em relação aos ambientes naturais como possibilidade de escalada, esta pesquisa descreveu a "Pedreira do Cafezal" de Londrina que embora localizada no perímetro urbano é um lugar amplo com diferentes vias e graus de dificuldade, onde o escalador pode se sentir um pouco mais em interação com os elementos da natureza sem muitas interferências urbanas, isso porque os acidentes naturais oferecidos pela própria rocha indicam desafios e incertezas no ato de ascensão. 
Para Dias (2008), as paredes/blocos de pedras no contexto urbano surgiram como possibilidades de prazer na limitação de encontrar lugares ou caminhos originais intocados, o que configurou no Rio de Janeiro o conceito de rochedismo. O rochedismo possui também uma dimensão estética a ser vivenciada numa escalada externa que proporciona panoramas, sensações de vertigem e exposições ao abismo durante a subida. Tais experiências estéticas colocam em interação homem e natureza denotando sensação de liberdade.

Ascender um paredão de rocha ou uma montanha é uma experiência corporal inseparável das atividades lúdicas, estéticas e imaginativas que movem o humano. Para Costa (2000), a fantasia do homem corajoso capaz de superar obstáculos, intempéries e entrar em contato direto com elementos da natureza, conferem à experiência corporal uma tonalidade singular e de plasticidade estimulante dos desejos e sonhos estruturantes do imaginário transgressor.

No texto Dos jogos de morte ao jogo de viver na montanha, Le Breton (2010) argumenta que o comportamento transgressor de arriscar-se em uma escalada na natureza pode fazer emergir o significado da própria existência. Existir estaria na vivência de que é possível, sempre, empurrar o limite para mais longe, numa superação sem fim, podendo provocar o autoconhecimento e o sentir-se mais poderoso ao sair ileso de um enfrentamento do perigo em meio natural. O homem que busca pela escalada em rocha sente necessidade de se desafiar para existir.

\section{Considerações Finais}

Na cidade de Londrina/PR foram identificados seis lugares para a pratica de 
escalada $^{12}$. Sendo cinco paredes em ambientes artificiais - três em academias de fitness, uma em um clube poliesportivo e a outra em uma escola de circo - e uma parede em ambiente natural - uma "Pedreira" rochosa.

Os frequentadores das paredes em academias de fitness são pessoas, no geral, iniciantes em busca de atividade física e/ou de lazer. No clube poliesportivo, identificamos também pessoas do universo empresarial e escolares que recebem orientações e vivencias para potencializar níveis emocionais e coletivos. Na escola de circo, há também a dimensão do treinamento de artistas circenses e de escaladores experientes.

Esta realidade permite-nos contrapor a ideia de que os praticantes de escalada (indoor ou não) em ambientes artificiais estão se preparando, principalmente, para vivenciar a escalada no ambiente natural, uma espécie de treino em razão da impossibilidade de acesso cotidiano às montanhas, rochas, entre outras.

As modalidades de escalada mais praticadas são: Top Rope e Boulder. Não há um biótipo e nível de experiência como exigências, nem mesmo definição de idade para escalar. Destaca-se que nos ambientes artificiais há equipamentos para escalar de forma a vivenciar o risco controlado e há cobrança de taxa financeira para praticar a atividade. Trata-se, sobretudo de negócio típico de uma sociedade constituída por indivíduos ávidos por emoções e por superação de suas próprias capacidades corporais.

A partir da escalada, considera que as atividades de aventura em ambiente artificializado estão cada vez mais presente no cenário urbano. Logo, o setor privado investe para ampliação da sua clientela. Por outro lado, o poder público poderia

\footnotetext{
${ }^{12}$ Durante a realização da pesquisa identificamos mais dois ambientes artificias de escalada em construção: Parede de escalada do Centro de Educação Física e Esporte (CEFE) da Universidade Estadual de Londrina e as Paredes do MUV Escalada Indoor. Por isso estes espaços ficarão para estudos futuros. Ainda, numa cidade vizinha de Londrina, há o Centro de Treinamento de Escaladores de Cambé (CETEC-Cambé/PR).
} 
fomentar políticas públicas de tais atividades para a população no geral. Contudo, para o bom funcionamento das atividades de aventura promovidas tanto pelo setor privado como pelo setor público, destacamos, concordando Schwartz e Carnicelli Filho (2006), a pertinência de formação qualificada de instrutores e de profissionais de Educação Física incumbidos da orientação técnica e emocional para atender interessados na experiência significativa oportunizada nas atividades de aventura.

Sobre a escalada no ambiente natural, a cidade de Londrina tem a "Pedreira do Cafezal" frequentada aos finais de semana, principalmente, por escaladores mais experientes. Ao ascender as vias rochosas, os escaladores rompem com a rotina dos dias e provocam experiências existenciais objetivadas na interação homem e natureza. O desafio de enfrentar as pedras naturais é o desafio ao mesmo tempo do enfrentamento da natureza humana. Desse modo, a escalada em ambiente natural se apresenta como exterior à dinâmica ordinária da vida, embora esteja orgânica e socialmente ligada a ela.

\section{REFERÊNCIAS}

BERNARDES, L. A. Atividades de aventura em ambientes artificiais. In: PEREIRA, D. W.; et al. (Org.). Entre o urbano e a natureza: a inclusão na aventura. V CBAA. Prefeitura Municipal de São Bernardo do Campo: Lexia, 2011. p. 103-112.

COSTA, V. L. M. Esporte de aventura e o risco na montanha: um Mergulho no Imaginário. São Paulo: Manole, 2000.

DIAS, C. A. G. Urbanidade da natureza: o montanhismo, o surfe e as novas configurações do esporte no Rio de Janeiro. Rio de Janeiro: Apicuri, 2008.

HONORATO, T.; XAVIER FILHO, E. Aspectos da escalada para formação profissional em educação física. In: LORO, A. P.; VINHA, M.; GOLIN, C. H. (Org.). Educação física: enfoques contemporâneos. Dourados: Ed. UFGD, 2013, p. 161-178.

LE BRETON, D. Dos jogos de morte ao jogo de viver na montanha: sobre o alpinismo solitário. In: PEREIRA, D. W.; et al. (Org.). Entre o urbano e a natureza: 
a inclusão na aventura. V CBAA. Prefeitura Municipal de São Bernardo do Campo: Lexia, 2010. p. 37-58.

LIPOVETSKY, G. A felicidade paradoxal: ensaio sobre a sociedade de hiperconsumo. São Paulo: Companhia das Letras, 2007.

MARINHO, A. Da busca pela natureza aos ambientes artificiais: reflexões sobre a escalada esportiva. 2001.136f. Dissertação (Mestrado). Faculdade de Educação Física da UNICAMP, Campinas, 2001.

MOREIRA, H.; CALEFFE, L. G. Metodologia da pesquisa para o professor pesquisador. Rio de Janeiro: Lamparina, 2008.

PEREIRA, D. W. Escalada. São Paulo: Odysseus, 2007.

SCHWARTZ, G. M.; CARNICELLI FILHO, S. (Desin) Formação profissional e atividades de aventura: focalizando os guias de "Rafting". Revista Brasileira de Educação Física e Esporte, São Paulo, v 20, n 2, p.103-09, abr/jun, 2006.

TRIVIÑOS, A. N. S. Introdução à pesquisa em ciências sociais: a pesquisa qualitativa em educação. São Paulo: Atlas, 1995.

UVINHA, R. R. As atividades de Aventura no contexto urbano: cenários e potencialidades. In: PEREIRA, D. W.; et al. (Org.). Entre o urbano e a natureza: a inclusão na aventura. V CBAA. Prefeitura Municipal de São Bernardo do Campo: Lexia, 2010. p. 159-168.

VARGAS, G. R.; SILVA, D. S.; AMARAL, S. C. F. Participação em grupo de escalada como uma prática de lazer. Licere, Belo Horizonte, v 18, n 4, p. 94-133, dez, 2015 .

\section{Endereço dos Autores:}

Tony Honorato

Campus Universitário da UEL

Rodovia Celso Garcia Cid Pr 445 Km 380

Londrina - PR - 86.051-990

Endereço Eletrônico: tonyhonoratu@gmail.com

Nayara Teixeira

Campus Universitário da UEL

Rodovia Celso Garcia Cid Pr 445 Km 380

Londrina - PR - 86.051-990

Endereço Eletrônico: nay-teixeira@hotmail.com

Ernani Xavier Filho

Campus Universitário da UEL

Rodovia Celso Garcia Cid Pr 445 Km 380 
Tony Honorato, Nayara Teixeira e Ernani Xavier Filho

Londrina - PR - 86.051-990

Endereço Eletrônico: piraju@uel.br 